\title{
Antimicrobial Profiling of Bacteria Isolated from Fish Sold at Informal Market in Mufakose, Zimbabwe
}

\author{
Claudious Gufe $\mathbb{D}^{1},{ }^{1}$ Tinashe Canaan Hodobo, ${ }^{1}$ Bernard Mbonjani, ${ }^{1}$ Otlia Majonga, \\ Jerikias Marumure, ${ }^{2}$ Shuvai Musari, ${ }^{1}$ Gilbert Jongi, ${ }^{1}$ Pious Vengesayi Makaya, ${ }^{1}$ \\ and Jairus Machakwa ${ }^{3}$ \\ ${ }^{1}$ Division of Veterinary Services, Diagnostics and Research Branch, Central Veterinary Laboratories, P.O. Box CY 551, Causeway, \\ Harare, Zimbabwe \\ ${ }^{2}$ Department of Biological Sciences, Faculty of Science, Bindura University of Science Education, P. Bag 1020, Bindura, Zimbabwe \\ ${ }^{3}$ Division of Veterinary Services, Veterinary Public Health Branch, P.O. Box CY551, Causeway, Harare, Zimbabwe
}

Correspondence should be addressed to Claudious Gufe; claudiousgufe3@gmail.com

Received 2 January 2019; Accepted 2 April 2019; Published 2 May 2019

Academic Editor: Joseph Falkinham

Copyright (c) 2019 Claudious Gufe et al. This is an open access article distributed under the Creative Commons Attribution License, which permits unrestricted use, distribution, and reproduction in any medium, provided the original work is properly cited.

\begin{abstract}
The number of infections caused by antibiotic resistant bacteria is rising worldwide. Fish from multisource pollution waters can harbour multidrug-resistant bacteria that can be disseminated to humans through eating or contact of contaminated fish. A crosssectional study was carried out to (i) isolate and phenotypically identify bacteria from 36 fish samples from informal market in Mufakose, Harare, and (ii) determine the antibiotic sensitivity pattern of the isolated bacteria against ten available antibiotics (ampicillin $10 \mu \mathrm{g}$, gentamycin $30 \mu \mathrm{g}$, penicillin G $10 \mu \mathrm{g}$, erythromycin $15 \mu \mathrm{g}$, tetracycline $30 \mu \mathrm{g}$, kanamycin $30 \mu \mathrm{g}$, neomycin $10 \mu \mathrm{g}$, cloxacillin $5 \mu \mathrm{g}$, lincomycin $15 \mu \mathrm{g}$, and sulfamethoxazole $25 \mu \mathrm{g}$ ) using the Kirby-Bauer disk agar diffusion method. Eight bacterial genera were isolated and identified, and they were Escherichia, Aeromonas, Staphylococcus, Pseudomonas, Citrobacter, Klebsiella, Enterobacter, and Proteus. Among the isolates, Escherichia coli was isolated most frequently (44\%) followed by Staphylococcus aureus (19\%), Enterobacter aerogenes (7\%), Aeromonas spp. (5\%), Proteus mirabilis (5\%), Citrobacter (5\%), and coagulase-negative Staphylococci (5\%) and the least frequent were Klebsiella (3\%) and Pseudomonas (3\%). All isolates were susceptible to gentamycin. Varying antibiotic resistance rates were observed to lincomycin (100\%), ampicillin (81\%), penicillin (67\%), erythromycin (65\%), tetracycline (63\%), neomycin (61\%), cloxacillin (43\%), kanamycin (24\%), and sulphamethoxazole (13\%). All the isolates were multidrug-resistant (resistant to at 3 or more drugs tested) except Proteus mirabilis. Proteus mirabilis has multiple antibiotic resistance (MAR) index of 0.2 , and the other isolated bacteria had MAR indexes greater than 0.2 ranging from 0.3 to 0.7 . Those MAR indexes above 0.2 showed that the bacteria isolates are from a high risk source where antibiotics were frequently used, possibly from sewage effluents. Isolation of enteric bacteria such as Escherichia coli is an indication of faecal contamination, and this poses a high risk to animal and human health. These significant findings call for effective risk assessment models and management plans that protect human, animal, and environmental health.
\end{abstract}

\section{Introduction}

In many countries, fish are consumed and are considered to be a good source of dietary protein. The fish provide highquality essential proteins. According to FAO [1], fish is the most important single source of high-quality protein providing about $16 \%$ of the animal protein consumed by the world's population. In Africa, fish constitutes about $17 \%$ of animal protein consumed [2]. Fish has high nutritional values such as low saturated fat and good source of essential fatty acids, the omega-3 fatty acids which cannot be synthesized by the human body. Fish are known to contain low fat and low cholesterol and to be highly digestible making them suitable to the infants, children, and elderly. It is 
relatively cheap compared to other meat products such as beef and poultry; hence, it is more affordable to most people.

From the perspective of microbiology, fish and related products are a potential health risk since they harbour important human pathogenic bacteria on or inside them. Bacterial infections might arise through improper handling and through the consumption of badly prepared fish. Several bacterial genera such as Escherichia, Listeria, Pseudomonas, Klebsiella, and Salmonella were isolated from fish and can indicate multisource pollution $[3,4]$. Most people get infected through contact while handling water or other constituents of fish living environments. The development of infectious diseases is also markedly affected by the physiological status of the consumer, for instance, immunocompromised or stressed individuals are quite susceptible to opportunistic infection as exemplified by people living with HIV and AIDS [5].

Banquero et al. [6] described aquatic systems as genetic reactors or hotspots for AMR genes where significant genetic exchange and recombination can occur, which can shape the evolution of future resistance profiles. Bacteria acquire resistance either through mutations in their genetic material or through a process called horizontal gene transfer. Resistance to antibiotics can be conferred by chromosomal or mobile genetic elements and achieved using four main strategies, namely, reduction of membrane permeability to antibiotics, drug inactivation, and rapid efflux of the antibiotics and mutation of cellular target $[7,8]$. A large part of the exchange of resistance genes takes place in the gastrointestinal tract [8]. After excretion, the potential resistant bacteria end up in the environment and near food products of animal origin. These food products are an important source of human infection, thus causing an increase in use of antibiotics, which favours the emergence of antibacterial resistance [9].

The number of infections caused by antibiotic-resistant bacteria is rising worldwide [8]. Some bacterial infections, e.g., salmonellosis, do not require treatment; however, if the infection is serious or invasive, antimicrobial drugs are commonly administered [7, 8]. Moreover, the overuse of antimicrobial drugs to prevent or treat infections in human and veterinary medicine contributes to the increased frequency and dissemination of AMR [10]. Irrational use of antimicrobials is associated with increased selection pressure on bacterial populations and favours survival and multiplication of resistant bacteria. Antimicrobial resistance is a naturally occurring phenomenon, and the resistance rates are kept at reasonably low levels; however, increased AMU can drive the rise in the rate of resistance. Drug resistance in isolates originating from wildlife, which are not influenced by selective pressures of antimicrobial drugs, is thought to be low. Nevertheless, Levy and Marshall [8] proposed that the fastest way to get rid of resistant bacteria is to outnumber them with sensitive bacteria.

Fish usually succumb to opportunistic bacterial infection due to physiological imbalance. Stress factors such as nutritional deficiencies, poor quality water, and overstocking are predisposing factors in the development of fish infections. Pathogenic bacteria are classified as indigenous or nonindigenous. Pathogenic bacteria common in fish include
Aeromonas species, which is ubiquitous in water in freshwater environments [11]. The same authors also added that indigenous bacteria which include Aeromonas, Clostridium, and Vibrio are widely distributed in aquatic environments in the warm tropical zones and estuarine environment. Salmonella, E. coli, and Shigella bacteria survival in water depends on many parameters such as biological (interactions with other bacteria) and physical factors such as temperature. The occurrence of nonindigenous bacteria such as $E$. coli, Salmonella, and Shigella dysenteriae in fish is normally as a result of faecal contamination.

Consequently, it has been strongly recommended that programmes to monitor the usage of antimicrobial agents and occurrence of antimicrobial resistance among animals, plants, and humans should be established [12]. This has been initiated in some countries; however, a major obstacle has been the lack of coordination and standardization both, over time or between countries, complicating comparisons. The appearance of antibiotic resistance among bacteria from animals has raised considerable concern due to the potential for transfer of resistant pathogens and commensal bacteria to the human population [13]. The safety of eating fish from informal market is not known; therefore, there is a need to assess and investigate the potential risk posed to human health by consuming fish sourced from the informal market. The fish on the informal market are from heavily contaminated Lake Chivero with untreated sewage and agricultural and industrial wastes. The main objective of this study was to isolate and identify bacteria from fish at the informal market in Mufakose and to determine the level of antibiotic resistance rates of the isolated bacteria against ten antibiotics.

\section{Materials and Methods}

2.1. Study Design and Sample Collection. This was a cross sectional study in which a total of 36 fish samples were collected from vendors along shopping centres in Mufakose, Harare, Zimbabwe, from mid-July to August 2017. A total of 36 fish samples were collected. Twelve fish samples were collected at the first visit and was repeated three times. Fish bought from vendors in Mufakose were collected in sterile plastic bags labelled with identities derived from location of collection. Fish samples were transported to the laboratory for testing in cooler boxes and tested on the same day. Samples were collected from the vendors using random sampling. Mufakose is a high-density suburb with a lot of informal markets along streets or and shopping centres.

2.2. Isolation and Identification of Bacteria. Ten grams of fish were cut into small pieces, placed in a labelled bottle containing peptone water, listeria-selective broth, and buffered peptone water. The contents were homogenised. The homogenate from peptone water was streaked using a sterile loop on blood agar and MacConkey, Skirrows, and Campylobacter agars for Vibrio and Campylobacter [14]. The streaked plates were incubated some aerobically and anaerobically at $37^{\circ} \mathrm{C}$ for 24 hours. For Campylobacter, incubation was done in anaerobic jars provided with Campylobacter gas generating sachets (Oxoid) [14]. Homogenate in Listeria 
selective broth was incubated for 24 hours at $37^{\circ} \mathrm{C}$. After incubation, the broth was streaked on Listeria agar and incubated for 24 hours at $37^{\circ} \mathrm{C}$ [14]. Homogenate in buffered peptone water was incubated for 24 hours at $37^{\circ} \mathrm{C}$. After incubation, $1 \mathrm{ml}$ of the homogenate was transferred into Rappaport Vassiliadis (RV) and incubated for 24 hours at $37^{\circ} \mathrm{C}$. On day three, a loopful of the sample was streaked on Xylose lysine deoxychocolate (XLD) and incubated for 24 hours at $37^{\circ} \mathrm{C}[14]$.

\subsection{Morphology and Biochemical Characterization of Isolated} Bacteria. The bacteria were identified using morphological characteristics, Gram staining, and biochemical tests as indicated in Figure 1 with some subcultured on selective differential media [14]. To identify the bacteria, morphological characteristics, a range of biochemical tests such as oxidase, motility, indole, citrate, lysine decarboxylase, urease, and triple sugar iron (TSI), and a range of sugars were performed. Autoclaved fish and uninoculated media were used as a negative controls and during biochemical testing, different ATCC organisms from Microbiologics (Staphylococcus aureus ATCC 33862, Escherichia coli ATCC 25922, Klebsiella pneumoniae ATCC 13883, Citrobacter freundii ATCC 8090, and Pseudomonas aeruginosa ATCC 27853) were used as positive controls. Table 1 shows some of the morphological characteristics used for bacterial identification such as colony colour, smell, and haemolysis on sheep blood agar. MacConkey agar was used as a selective and differential media, differentiating lactose fermenters from nonlactose fermenters.

2.4. Antibiotic Profiling. At least 4-5 well isolated colonies of the same morphological type from a pure culture were selected and swabbed using a sterile cotton swab [14]. The colonies were transferred into sterile $0.85 \%$ physiological saline water (PBS), and the bacteria emulsified until the turbidity is similar to the $0.5 \mathrm{McF}$ arland standard. Another sterile swab was immersed in PBS suspension, and the swab was pressed against the walls of the bijoux bottle above the fluid level to remove excess fluid. The swab was then streaked in 3 different directions over the surface of a plate of Mueller-Hinton agar (MHA) such that a uniform wellspread-out inoculation is achieved. The inoculated plateswere allowed to stand for 3-5 minutes so that the inoculum can dry. The antibiotic disc dispenser was retrieved from the refrigerator and left on the bench for 15 minutes at room temperature. The standard antibiotic disks (Oxoid) containing sulfamethoxazole-trimethoprim combination $(25 \mathrm{mcg})$, penicillin $(10 \mathrm{mcg})$, tetracycline $(30 \mathrm{mcg})$, gentamycin $(10 \mathrm{mcg})$, erythromycin $(15 \mathrm{mcg})$, ampicillin $(10 \mathrm{mcg})$, kanamycin $(30 \mathrm{mcg})$, neomycin $(10 \mathrm{mcg})$, cloxacillin $(5 \mathrm{mcg})$, and lincomycin $(15 \mathrm{mcg})$ were dispensed onto well-labelled inoculated MHA plates using the disc dispenser. The antibiotic disks used were based on their availability at the laboratory at the time of the study. The plates were allowed to stand for few minutes and were incubated at $37^{\circ} \mathrm{C}$ for 24 hours within 15 minutes of applying [14]. Antibiotic sensitivity was checked by measuring the zone of inhibition (zone of clearance) from the back of the plate to the nearest $\mathrm{mm}$ using a ruler or caliper. The zone of inhibitions were recorded and used to establish if the bacterial isolates were resistant, intermediate, and susceptible using reference books and WHONET. The bacteria were reported as sensitive (S), intermediate (I), or resistant (R) to each of the antibiotics used in the test.

\subsection{Multiple Antibiotic Resistance (MAR) among the Isolated} Bacteria. The MAR index when applied to a single isolate is defined as $\mathbf{a} / \mathbf{b}$, where " $\mathbf{a}$ " represents the number of antibiotics to which the isolate was resistant and "b" represents the number of antibiotics to which the isolate was exposed. For example, if the isolate was exposed to twelve antibiotics and was tolerant to six antibiotics, the index for the isolate would be $6 / 12$ or 0.50 [15]. The MAR index was calculated for all the bacterial isolates.

2.6. Data Analysis. Prevalence rates of bacteria isolates was calculated as the number of times the bacteria species was identified over the total number of all the bacteria species identified. Resistance rates were calculated for each antibiotic and each bacterial isolates as the number of species isolates resistant over the total number of species tested. The overall resistance rates of each antibiotic were calculated as the number of bacteria resistant to antibiotic over total number of bacteria isolates tested.

\section{Results}

3.1. Bacteria Isolation and Identification. The bacteria isolated were E. coli, Aeromonas species, Citrobacter species, Staphylococcus aureus, Klebsiella species, Enterobacter aerogenes, Proteus mirabilis, Pseudomonas species, and coagulate-negative Staphylococci which were identified using morphological properties, Gram staining, and series of biochemical tests. Escherichia coli (24 out of 60) was the most dominant species among the isolated isolates from fish samples as indicated in Figure 2. Figure 2 below shows the percentage prevalence of the isolated bacteria: E. coli (40\%), Staphylococcus aureus (17\%), Aeromonas species (15\%), Enterobacter aerogenes (7\%), Proteus mirabilis (5\%), Citrobacter species (5\%), coagulase-negative Staphylococci (5\%), Pseudomonas (3\%), and Klebsiella (3\%).

\subsection{Antimicrobial Susceptibility and Resistance Testing.} All the identified isolates were susceptible to gentamycin, and all the isolates were resistant to lincomycin. The isolated bacteria showed variable resistance rates to each antibiotic as shown in Table 2. Overall resistance rates for each antibiotic for all the organisms identified are lincomycin (100\%), ampicillin (81\%), penicillin (67\%), erythromycin (65\%), tetracycline (63\%), neomycin (61\%), cloxaxillin $(43 \%)$, kanamycin (24\%), and sulphamethaxole (13\%). All the isolates have a $100 \%$ resistance to at least three antibiotics used except for Proteus mirabilis which was $100 \%$ resistant to 


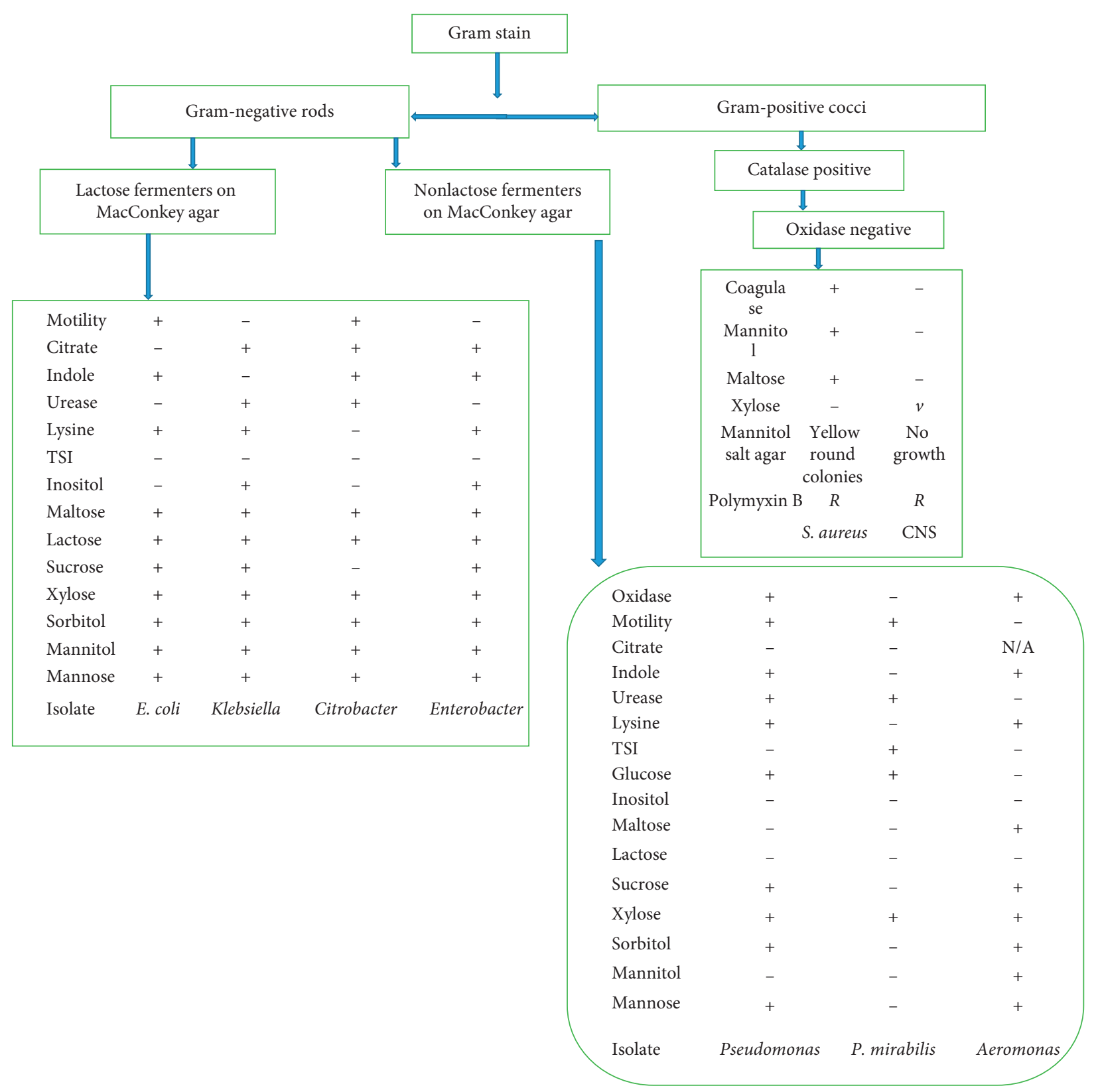

FIgURE 1: Flow diagram showing Gram staining and some biochemical tests used to identify different bacterial isolates.

TABLE 1: Colony morphology of the suspected bacteria.

\begin{tabular}{lcc}
\hline Blood agar & MacConkey agar & Suspected bacteria \\
\hline Yellow round raised smooth shiny colonies & Tiny pink colonies & Staphylococcus species \\
Grey round flat haemolytic with coliform smell & Bright pink round colonies & E. coli \\
Grey round raised with coliform smell & Pink round colonies & Coliforms \\
Grey, flat, round, haemolytic colonies with foul smell & Pale round raised colonies & Aeromonas species \\
Blue-green flat, round, haemolytic fruity smell & Pale round raised colonies & Pseudomonas species \\
Large grey mucoid colonies & Pale-pink colonies & Klebsiella/Enterobacter species \\
Large grey mucoid colonies & Pink round colonies & Klebsiella/Enterobacter species \\
Grey swarming colonies with foul smell & Pale round colonies & Proteus species \\
\hline
\end{tabular}

only two antibiotics. We concluded that all the bacterial isolates from fish sold at informal market were multidrug resistant except for Proteus mirabilis. Few species of
Citrobacter and Klebsiella were intermediate and was not considered resistant but was bunched in the susceptible group. 


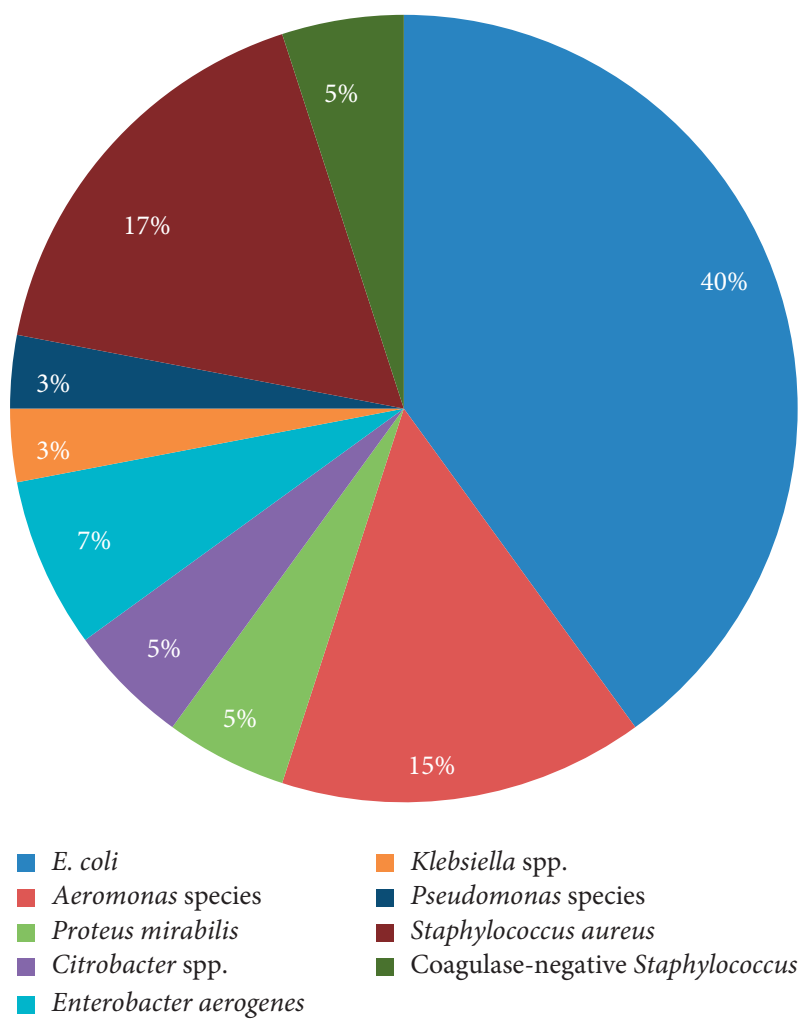

FIgURE 2: Prevalence rate of the isolated bacteria.

The MAR index of all isolates show values higher than 0.2 except Proteus mirabilis which has MAR index of 0.2 (Table 3). From Table 3, all the isolated bacteria were multidrug resistant (resistant to 3 or more antibiotics) except for Proteus mirabilis. Table 3 also shows the MAR indexes of the isolated bacteria ranging from 0.2 to 0.7 . Escherichia coli, Enterobacter aerogenes, and Staphylococcus aureus have the highest MAR index value of 0.7 . The trend of antimicrobial resistance is shocking for the bacterial species isolated from fish sold at informal market.

\section{Discussion}

4.1. Bacteria Isolation and Identification. Most outbreaks of food poisoning associated with fish are derived from the consumption of raw or insufficiently heat-treated fish, which may be contaminated with bacteria from water environment (Vibrio spp. and C. botulinum) or terrestrial sources ( $C$. perfringens, Salmonella spp., Shigella spp., Staphylococcus spp., and $V$. cholerae), or fish products recontaminated after heat processing. In the case of poor hygiene, the contamination of fish and fish products may increase due to unsanitary procedures, the rotation of the assigned duties of workers, handling, and airborne microorganisms during packing of the product. The 8 bacteria genera isolated in this study (Figure 1) corroborate to 4 bacteria genera isolated from edible fish in Zimbabwe in [3] (Pseudomonas, Escherichia, Klebsiella, and Proteus) and to 3 bacteria genera in [4] (Escherichia, Staphylococcus and Pseudomonas). This study also corroborates internationally to 3 genera (Pseudomonas, Escherichia, and
Staphylococcus) isolated from fish in India in [16]. The prevalence rates of the isolated bacteria shown in Table 1 ( $E$. coli was the most abundant followed by $S$. aureus) were not in agreement with those reported by [4] (S. aureus was the most abundant followed by E. coli). Isolation and identification of enteric bacteria (E. coli, P. mirabilis, Klebsiella, Citrobacter species, and E. aerogenes), S. aureus, CNS, and Pseudomonas species indicate multisource pollution of fish from sewage effluents, humans during handling, and industrial and agricultural wastes. From this study, it is found that the presence of haemolytic E. coli can cause diarrhoea mainly in kids and immunosuppressed individuals. The presence of E. coli and other coliforms (Klebsiella, Citrobacter species, and E. aerogenes) in food is a clear indication of environment and faecal pollution either from humans and or from animals as well as poor handling practices [17-19]. The presence of E. coli can indicate the presence of other disease-causing pathogens (health risk) in the fish even if they were not isolated. According to [4], enteric bacteria were isolated from fish ponds, where animal manure was added indicating faecal contamination. In Harare, there are challenges in sewage management, and raw sewage sometimes ends up in fresh water sources like rivers. When sewage pipes burst, raw sewage contaminates the environment including water sources. Some sewage contaminated river systems flow into Lake Chivero where most of the fishing activities are done. There is also a problem of bursting of sewage pipes, thus exuding raw untreated sewage from the high-density suburbs. Fish are contaminated from the sewage and industrial wastes [20] as well as from poor handling techniques by vendors.

Proteus mirabilis is also a commensal in warm bodied animals; therefore, its present might be due to faecal contamination. P. mirabilis is an opportunistic pathogen which primarily affects an individual whose immune system is compromised. The presence of Aeromonas spp. indicates that the fish were infected in the lake. This is in concurrence with [14], stipulating that pathogenic bacteria common in fish include Aeromonas species which is ubiquitous in water in freshwater environments. The presence of $S$. aureus and CNS means that the fish were contaminated from human and animal wastes at the source (lake) or during handling. In this study, there was no Salmonella, Listeria, Vibrio, and Shigella genera, which were isolated by $[3,4,16,20]$. In our study, we isolated more bacteria genera (8) than that in $[3,4,16,20]$.

4.2. Antibiotic Resistance. The study of antibiotic resistance in pathogenic bacteria from fish is important, as it might indicate the extent of alteration of water ecosystems by anthropogenic activities. Actually, water bacteria could be indigenous to aquatic environments, or exogenous, transiently and occasionally present in the water as a result of shedding from animal, vegetal, or soil surfaces. The resistance of the strains to antibiotics could be explained by the possibility of the heavy use of these compounds in aquaculture, several of which are non-biodegradable, thus increasing antibiotic selective pressure in water, facilitating the transfer of antibiotic-resistant determinants between aquatic 
TABLE 2: Resistance rate of bacteria to antibiotics.

\begin{tabular}{|c|c|c|c|c|c|c|c|c|c|c|}
\hline Bacteria & PEN & SXT & ERY & GEN & NEO & KAN & $\mathrm{CLO}$ & AMP & TET & LIN \\
\hline E. coli & 100 & 0 & 50 & 0 & 100 & 0 & 50 & 88 & 67 & 100 \\
\hline Aeromonas species & 0 & 100 & 100 & 0 & 0 & 100 & 0 & 0 & 0 & 100 \\
\hline Proteus mirabilis & 0 & 0 & 0 & 0 & 0 & 0 & 0 & 0 & 100 & 100 \\
\hline Citrobacter spp. & 67 & 0 & 100 & 0 & 100 & 0 & 0 & 100 & 67 & 100 \\
\hline Enterobacter aerogenes & 100 & 25 & 100 & 0 & 100 & 0 & 100 & 100 & 100 & 100 \\
\hline Klebsiella spp. & 100 & 0 & 50 & 0 & 100 & 0 & 50 & 50 & 50 & 100 \\
\hline Pseudomonas species & 0 & 0 & 100 & 0 & 0 & 0 & 100 & 100 & 0 & 100 \\
\hline Staphylococcus aureus & 40 & 30 & 70 & 0 & 0 & 100 & 40 & 100 & 80 & 100 \\
\hline Coagulate-negative Staphylococcus & 0 & 0 & 100 & 0 & 0 & 0 & 0 & 100 & 0 & 100 \\
\hline
\end{tabular}

TABLE 3: Multidrug resistance and MAR index of the isolated bacteria.

\begin{tabular}{lcc}
\hline Isolates & MDR isolate & MAR index \\
\hline Citrobacter species & Positive & 0.5 \\
E. coli & Positive & 0.7 \\
Enterobacter aerogenes & Positive & 0.7 \\
Klebsiella species & Positive & 0.5 \\
Proteus mirabilis & Negative & 0.2 \\
S. aureus & Positive & 0.7 \\
CNS & Positive & 0.3 \\
Pseudomonas aeruginosa & Positive & 0.4 \\
Aeromonas species & Positive & 0.4 \\
\hline
\end{tabular}

bacteria, including fish and human pathogens, and allowing the presence of residual antibiotics in commercialized fish and shellfish products $[12,21,22]$.

The identified isolates were multiresistant to various antibiotics used except for Proteus mirabilis. Indeed, all bacteria were sensitive to gentamicin, and this corroborates a study by [3]. Baquero et al. [6] found that all strains of $A$. hydrophila were sensitive to gentamicin, and this is in agreement with all the Aeromonas species tested in this study. Antimicrobials in waste water are increasingly found and potentially have an important role in the rise and selection of antimicrobial resistance in the environment $[12,21]$. The MAR index of all isolates show values higher than 0.2 except for Proteus mirabilis which has a MAR index of 0.2. Those multidrug-resistant bacteria with MAR indexes greater than 0.2 indicate that they are from the high-risk source where antibiotics are frequently used, possibly faecal contamination. Due to indiscriminate use of antibiotics, the microorganisms might have developed resistance towards several antibiotics.

\section{Conclusion}

Raw sewage poured into lakes and rivers contaminates these water bodies with bacteria originating from human waste. Fish harvested from contaminated water bodies meant for human consumption are potential sources of human pathogenic bacteria. The contaminated water can also be associated with illness in the fish. The isolated multidrugresistant bacteria pose high risk to human, animal, and environment health. Strict rules and monitoring activities combined with food safety training fishermen, vendors, and consumers on various aspects of good hygiene practices are strongly recommended.

\section{Data Availability}

The data used to support the findings of this study are available from the corresponding author upon request.

\section{Additional Points}

Recommendation. (i) Thorough investigation of both phenotypic and genotypic antibiotic resistance on pathogenic bacteria isolated from fish and water bodies in Zimbabwe must be done. (ii) Also, people must thoroughly cook the fish they buy from open market to prevent infections from these pathogens. (iii) The city must minimize or control sewage effluent to enter the water bodies to prevent pollution.

\section{Conflicts of Interest}

The authors declare that they have no conflicts of interest.

\section{References}

[1] FAO, "Social issues in small-scale fisheries: how a human rights perspective can contribute to respective fisheries," in Proceedings of the Presentation to FAO Committee of Fisheries No 27, Rome, Italy, March 2007.

[2] E. H. Allison, A. L. Perry, M.-C. Badjeck et al., "Vulnerability of national economies to the impacts of climate change on fisheries," Fish and Fisheries, vol. 10, no. 2, pp. 173-196, 2009.

[3] P. Manhondo, R. K. Gono, J. Muzondiwa, and B. Mafa, "Isolation and identification of pathogenic bacteria in edible fish: a case study of bacterial resistance to antibiotics at Lake Chivero, Zimbabwe," African Journal of Agricultural Research, 2018, In press.

[4] P. R. Sichewo, R. K. Gono, J. Muzondiwa, and W. Mungwadzi, "Isolation and identification of pathogenic bacteria in edible fish: a case study of rural aquaculture projects feeding livestock manure to fish in Zimbabwe," International Journal of Current Microbiology and Applied Sciences, vol. 3, no. 11, pp. 897-904, 2014.

[5] S. C. Rastogi, Essentials of Animal Physiology, New Age International Limited, New Delhi, 4th edition, 2007.

[6] F. Banquero, J. L. Martínez, and R. Canton, "Antibiotics and antibiotic resistance in water environments," Current Opinion in Biotechnology, vol. 19, no. 3, pp. 260-265, 2008.

[7] C. Baker-Austin, M. S. Wright, R. Stepanauskas, and J. V. McArthur, "Co-selection of antibiotic and metal resistance," Trends in Microbiology, vol. 14, no. 4, pp. 176-182, 2006. 
[8] S. B. Levy and B. Marshall, "Antibacterial resistance worldwide: causes, challenges and responses," Nature Medicine, vol. 10, no. S12, pp. S122-S129, 2004.

[9] R. I. Aminov, "The role of antibiotics and antibiotic resistance in nature," Environmental Microbiology, vol. 11, no. 12, pp. 2970-2988, 2009.

[10] WHO, Critically Important Antimicrobials for Human Medicine: Categorization for the Development of Risk Management Strategies to Contain Antimicrobial Resistance Due to NonHuman Antimicrobial Use: Report of the Second, WHO Expert Meeting, Copenhagen, Denmark, 2007.

[11] B. U. Ibrahim, J. Baba, and M. S. Sheshi, "Isolation and identification of bacteria associated with fresh and smoked fish (Clarias gariepinus) in minna metropolis, Niger state, Nigeria," Journal of Applied and Environmental Microbiology, vol. 2, no. 3, pp. 81-85, 2014.

[12] A. Alonso, P. Sanchez, and J. L. Martinez, "Environmental selection of antibiotic resistance genes. Minireview," Environmental Microbiology, vol. 3, no. 1, pp. 1-9, 2001.

[13] F. C. Cabello, "Heavy use of prophylactic antibiotics in aquaculture: a growing problem for human and animal health and for the environment," Environmental Microbiology, vol. 8, no. 7, pp. 1137-1144, 2006.

[14] B. Markey, F. Leonard, M. Archambault, A. Cullinane, and D. Maguire, Clinical Veterinary Microbiology, Oxford University Press, New York, NY, USA, 2nd edition, 2013.

[15] M. C. Liberto, G. Matera, A. Quirino et al., "Phenotypic and genotypic evaluation of slime production by conventional and molecular microbiological techniques," Microbiological Research, vol. 164, no. 5, pp. 522-528, 2009.

[16] K. Sujatha, P. Senthilkumar, S. Sangeeta, and M. D. Gopalakrishnan, "Isolation of human pathogenic bacteria in two edible fishes, Priacanthus hamrur and Megalaspis cordyla at Royapuram waters of Chennai, India," Indian Journal of Science and Technology, vol. 4, no. 5, pp. 539-541, 2011.

[17] K. K. Chao, C. C. Chao, and W. L. Chao, "Suitability of the traditional microbial indicators and their enumerating methods in the assessment of faecal pollution of subtropical freshwater environments," Journal of Microbiology, Immunology and Infection, vol. 36, pp. 288-293, 2003.

[18] E. I. Eze, B. C. Echezona, and E. C. Uzodinma, "Isolation and identification of pathogenic bacteria associated with frozen mackerel fish (Scomber scombrus) in a humid tropical environment," African Journal of Agricultural Research, vol. 6, no. 7, pp. 1918-1922, 2011.

[19] S. O. Yagoub, "Isolation of Enterobacteria and Pseudomonas SPP. from raw fish sold in fish market in Khartoum State," Journal of Bacteriology Research, vol. 1, no. 7, pp. 85-88, 2009.

[20] S. Jahan, M. A. S. Jewel, M. A. Haque et al., "Current status of bacterial contamination in some fish species of Bakkhali River Estuary, Bangladesh," Archives of Agriculture and Environmental Science, vol. 4, no. 1, pp. 96-100, 2019.

[21] A. J. Alanis, "Resistance to antibiotics: are we in the postantibiotic era?," Archives of Medical Research, vol. 36, no. 6, pp. 697-705, 2005.

[22] C. Seiler and T. Berendonk, "Heavy metal driven co-selection of antibiotic resistance in soil and water bodies impacted by agriculture and aquaculture," Frontiers in Microbiology, vol. 3, p. 399, 2012. 


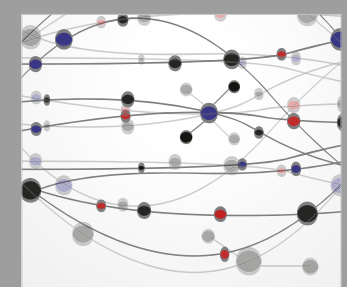

The Scientific World Journal
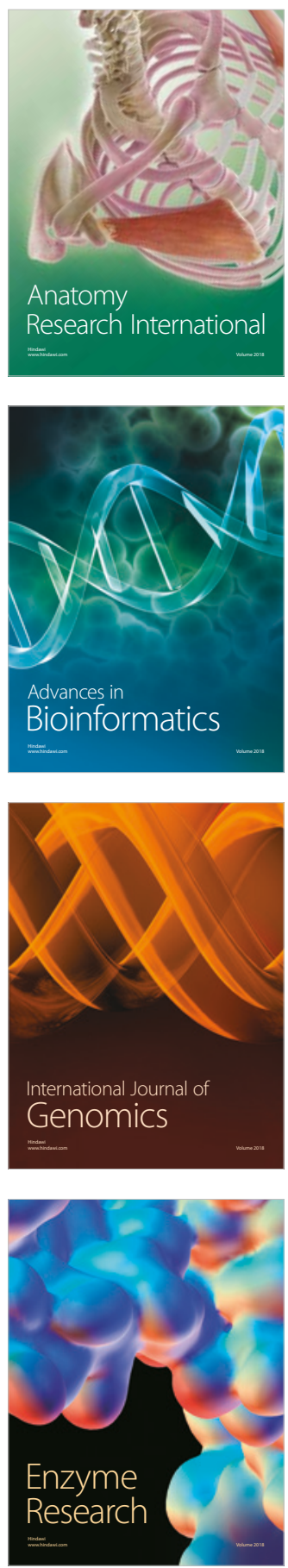
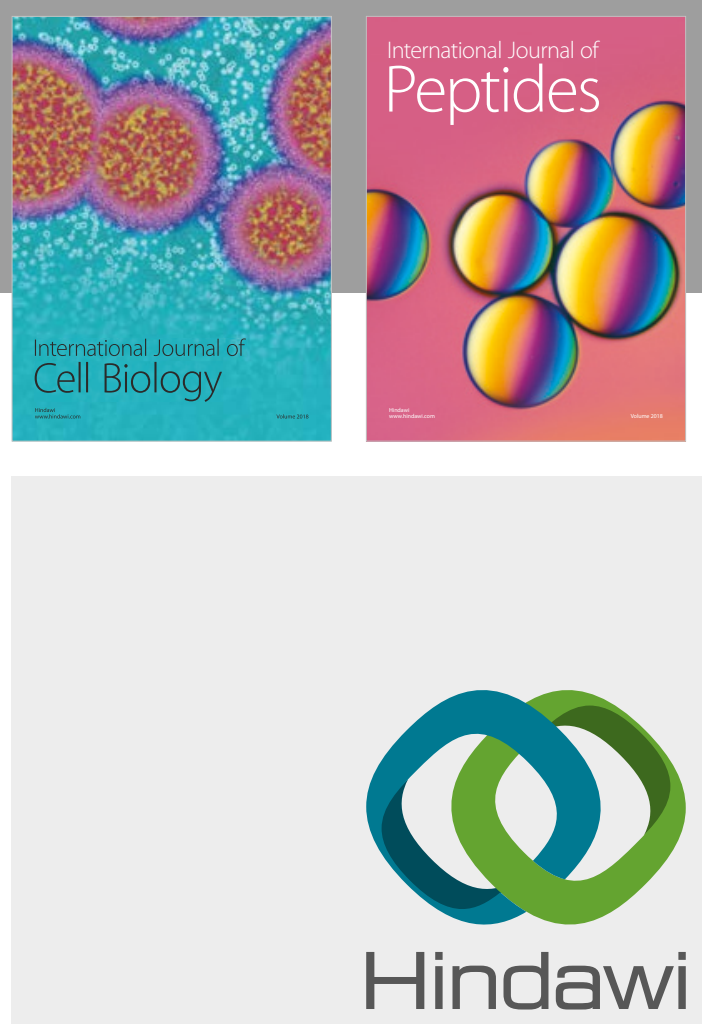

Submit your manuscripts at

www.hindawi.com
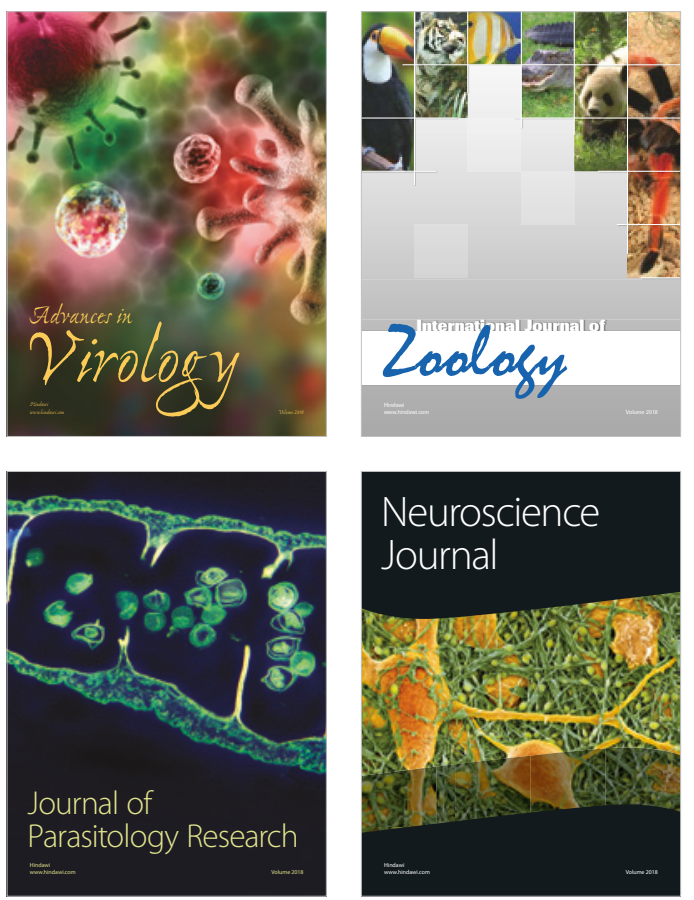
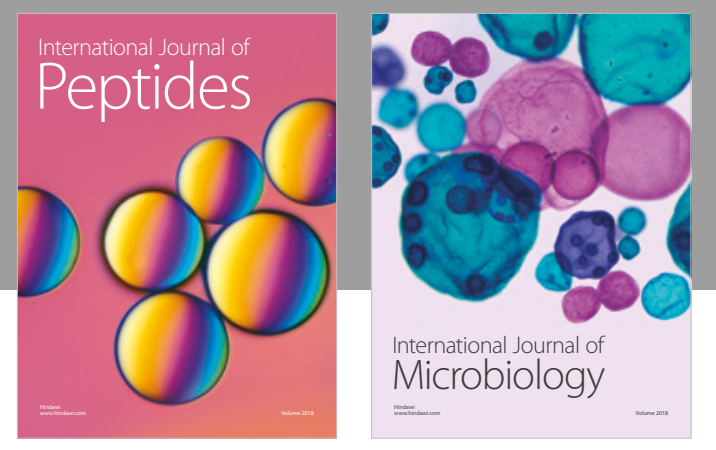

nternational Journal of Microbiology
Journal of
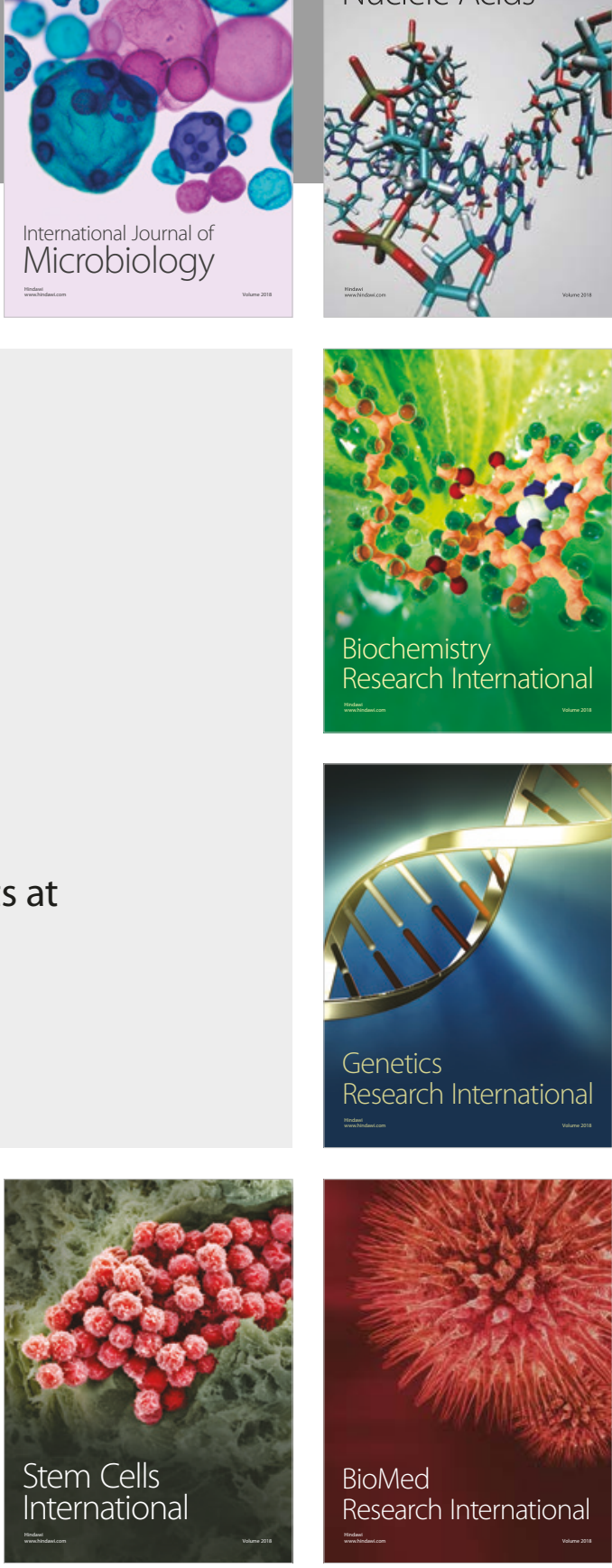
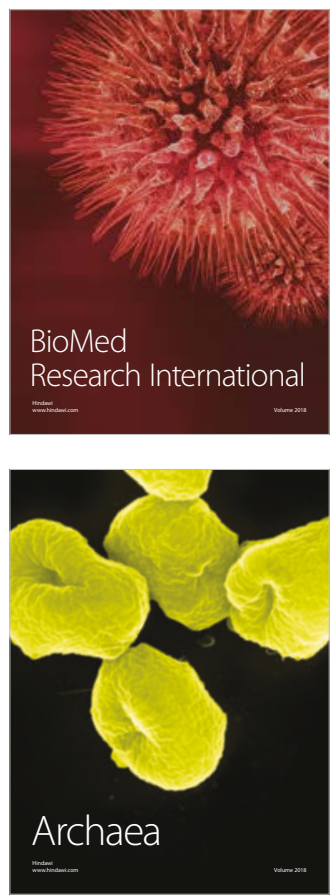